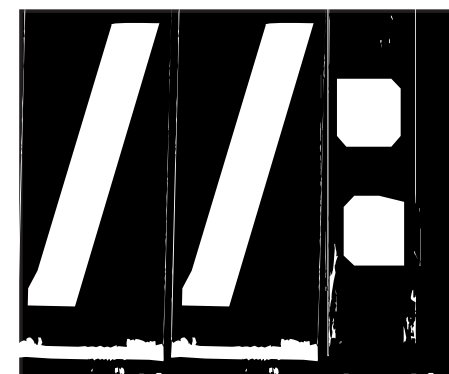

educa"ción y co"municación 4: 151-152 Mayo 2012

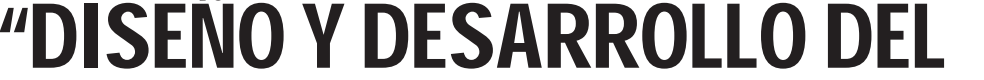
乎 42

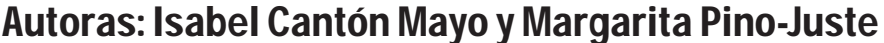

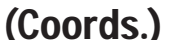

$\$ \square+000$

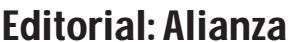

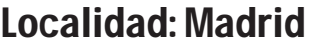

Issabel Cantón Maro

Margarita Pino-Juste

[coords]

\section{Diseño y desarrollo del currículum}

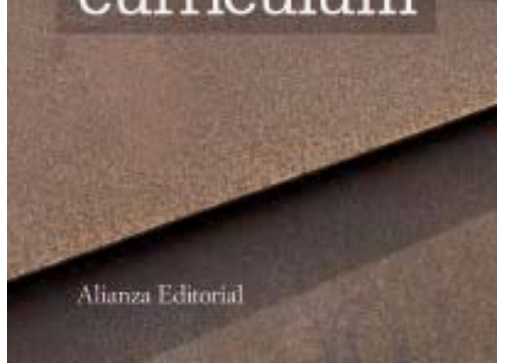

Mario Moguel González

Profesor de Secundaria y miembro del Grupo de Investigación "Educom”. 


\section{II: Bibliotecas, Lectura y TICs}

$\mathrm{E}^{\prime}$ currículum ha evolucionado en los últimos tiempos, pero sigue dando respuesta a interrogantes eternos e intermitentes de la envergadura de qué, cómo y cuándo enseñar, del mismo modo, que cuestiona el qué, cómo y cuándo evaluar. Un discurso persistente que se articula en cuanto a las respuestas según los contextos y los tiempos (personas y épocas). En este sentido, el libro "Diseño y desarrollo del currículum" (2011) editado por Alianza y coordinado por las profesoras Isabel Cantón Mayo (Universidad de León) y Margarita Pino-Juste (Universidad de Vigo) opta por enfocar este entramado con una mirada calidoscópica, no solamente por la pluralidad de autores (con un total de 21 firmas de, por ejemplo, Universidades como la de Oviedo, La Laguna o UNED, entre otras) sino también de temáticas que enfocan el currículum: desde el diseño a las competencias básicas, teniendo presente las tecnologías de la información y la comunicación o la inclusión sociocultural. Y todo se nutre con una visión (de cuatro) contextos específicos de unidades didácticas (sea infantil, primaria, secundaria o de la escuela oficial de idiomas) -y ahí hemos de destacar la presencia de profesorado no universitario-.

Un libro escrito en clave de aportación a un debate plural con la intención de constituirse, desde las intenciones de profesionales de la educación, en ofrecernos su experiencia y sensibilidad sobre la temática curricular. Es decir, para argumentar y mostrar su posicionamiento se opta, en la mayoría de los casos, por una justificación introductoria (entendida como una base epistemológica) y seguidamente dar a conocer su parecer, argumentado y, en ocasiones, ejemplificado (comprendiéndola como un acercamiento a la práctica). El diseño apriorístico del boceto se convierte en un instrumento para el conocimiento y la intervención, pues la práctica desde el desarrollo es lo que le da sentido. Por ello, consideramos apropiada la lectura, estudio y consulta del texto que reseñamos como un referente para los futuros docentes y, para los que ejercemos esta profesión interminable en cuanto a los requerimientos del saber y la sensibilidad. La comunión entre la teoría y la práctica es un principio que se persigue en nuestro quehacer profesional y, por ello, las profesoras universitarias Isabel y Margarita coordinan propuestas teóricas y prácticas, para su utilidad y uso.

Un trabajo con la intención de contribuir. Una contribución a un espacio de la enseñanza imprescindible, y de lo imprescindible hemos de hacer lo necesario y obligatorio. Una lectura que aconsejamos... con la opción de hacerlo de forma lineal o de un capítulo a otro, pues la autonomía de un capítulo se termina entendiendo cuando se finaliza la lectura y se observa que las ideas se complementan y completan de la misma manera que se integran y perfeccionan a partir de una segunda relectura.

Lejos de admitir en exclusividad la definición de currículum establecida en la LOE en su articulado 6 como "el conjunto de objetivos, competencias básicas, contenidos, métodos pedagógicos y criterios de evaluación" la reconsideración se apropia de nuestra voluntad docente pues es eso y mucho más donde la invisibilidad de las intenciones del currículum se evidencia una vez tras la lectura y reflexión del presente libro. 